\title{
LA COMUNICACIÓN PARAVERBAL EN MANUALES ESPAÑOLES DE ELOCUENCIA FORENSE DEL SIGLO XIX
}

\author{
Susana RIDAO RODRIGO \\ Universidad de Almería
}

\section{RESUMEN}

El objetivo de este artículo es analizar la información sobre comunicación paraverbal que aportan manuales españoles de elocuencia forense publicados en el siglo XIX. En concreto, las obras analizadas son: Sainz de Andino (1847[1828]), Enciso Castrillón (1840), Corradi (1843), Saurí y Lleopart (1847), Pérez de Anaya (1848), López (2013[1849]) y León y Olarrieta (1862). Como conclusión destaca que el primer manual publicado es el que contiene más información sobre comunicación paraverbal, seguido de Enciso Castrillón (1840) y Corradi (1843). Del mismo modo, hay que subrayar que en buena parte de las obras estudiadas se le otorga bastante protagonismo a las pausas.

PALABRAS CLAVE: elocuencia forense, oratoria, comunicación paraverbal, voz.

\section{AbSTRACT}

The aim of this paper is to analyze the information about the paraverbal communication provided by Spanish manuals of forensic eloquence published in the 19th century. Specifically, the works analyzed are: Sainz de Andino (1847[1828]), Enciso Castrillón (1840), Corradi (1843), Saurí y Lleopart (1847), Pérez de Anaya (1848), López (2013[1849]) and León y Olarrieta (1862). In conclusion, the first published manual is the one that contains more information on paraverbal communication, followed by Enciso Castrillón (1840) and Corradi (1843). In the same way, it should be emphasized that in many of the works studied the pauses have a prominent role.

KEYWORDS: forensic eloquence, oratory, paraverbal communication, voice. 


\section{INTRODUCCIÓN}

Desde tiempos pretéritos distintos autores han reflexionado sobre la descripción del discurso perfecto, aunque es en el último siglo -y aún más en las últimas décadas- cuando se han incrementado notoriamente las investigaciones de esta naturaleza. A colación de esta cuestión, conviene incluir el siguiente fragmento en el que Cicerón ya apuntaba a la dificultad de llevar a la práctica el ideal de orador perfecto:

Analicemos, pues, Bruto, si podemos, ese orador que nunca vio Antonio o que nunca existió en absoluto, del cual, si bien no podemos dar una imagen definida -cosa que el mismo Antonio decía que apenas a un dios le ha sido concedido-, al menos sí podremos quizá decir cómo debe ser (Cicerón 2013: 45).

Efectivamente, las civilizaciones griega y romana dejaron un importante legado describiendo las características del buen orador. Estas obras dictaminaron que la palabra per se no resulta elocuente, como consecuencia de que en el mensaje que transmite el orador también participa el propio emisor, así como la actitud, el gesto o la expresión facial (Hernández Guerrero y García Tejera 2008: 234). Habida cuenta de que el ser humano es sociable por naturaleza, la comunicación resulta imprescindible en el día a día de cualquier individuo (Laborda Gil 2014: 12). Los estudios tradicionales sobre retórica y oratoria concedían suma relevancia a la comunicación verbal, relegando a un segundo plano -e incluso olvidando en algunos casostanto la comunicación paraverbal como la comunicación no verbal. Para el investigador Poyatos (1994), los trabajos sobre comunicación y lenguaje poseen el error común de no haber observado la relación inseparable del trinomio palabra-paralenguaje-kinésica. En realidad, la complejidad de hablar correctamente en contextos formales está determinada por la multitud de variables que entran en juego (Cortés 2017: 13).

Con respecto a cómo se transmite la información cuando un emisor manda un mensaje a un receptor, el enfoque tradicional otorgaba un salomónico $33 \%$ a la comunicación verbal, otro $33 \%$ a la comunicación paraverbal y el $33 \%$ restante a la comunicación no verbal. En cambio, a través de experimentos científicos Mehrabian (1972) ofreció datos muy diferentes: $7 \%$ para la comunicación verbal, $38 \%$ para la voz y $55 \%$ para el lenguaje corporal. Ya entrados en el siglo XXI, van-der Hofstadt (2005: 20) aporta esta distribución de porcentajes: 10-20\% los elementos verbales, 40-50\% los elementos paraverbales y $40 \%$ los elementos no verbales. Menos precisa resulta la distribución de Orzáiz (2009), quien sostiene que la comunicación verbal alcanza el $20 \%$, de manera que el $80 \%$ restante le corresponde conjuntamente tanto a la comunicación paraverbal como a la comunica- 
ción no verbal. El elemento común que presentan estas investigaciones es descender el porcentaje otorgado a la palabra. Esto conlleva que el buen orador no solo ha de preparar el contenido de su discurso, sino que debe preocuparse en mayor medida por la puesta en escena. A propósito de esta cuestión, considera Albaladejo que en la actio el orador no puede ser neutro, dado que en ese caso el hablante perdería bastante fuerza persuasiva si no prioriza los medios auditivo y visual que acompañan al texto (1990: 167).

\section{LA COMUNICACIÓN PARAVERBAL}

Para comenzar este epígrafe se ha de tomar en consideración que Sánchez Pérez (2015: 52) reflexiona que sobre la ya asentada estructura tripartita de comunicación verbal, paraverbal y no verbal existe una borrosa frontera entre la comunicación paraverbal y no verbal, porque «... el sistema de comunicación paraverbal también es «no verbal» ${ }^{1}$, a la vez que evoca el carácter indisociable que caracteriza a estos tres elementos, en sintonía con Poyatos (1994). Según Sánchez Pérez (2015: 54), el lenguaje no verbal -incluye tanto el paralenguaje como la comunicación no verbalposee los siguientes cometidos:

1) transmite actitudes, sentimientos y emociones,

2) acompaña o complementa el lenguaje oral,

3) refuerza, enfatiza o matiza el habla,

4) reemplaza o sustituye en ocasiones a las palabras,

5) contradice lo dicho verbalmente,

6) regula el flujo de la comunicación, y

7) orienta para interpretar el lenguaje verbal.

Se entiende por paralenguaje «... el estudio de las variaciones no lingüísticas dentro del contexto del discurso, es prestar atención a lo que acompaña al contenido vocal, se trata de prestar atención a cómo se dicen las cosas: tono, volumen, ritmo, pausas y silencios» (Sánchez Pérez 2015: 59). Todos los componentes paraverbales han de ser utilizados de manera coherente, de forma que la potencia de la voz, la entonación, los silencios y los distintos ritmos desembocan tanto en gestos como en expresividad y genera que el auditorio desee escuchar al hablante (Bang-Rouhet 2009: 114). La voz debe ser entendida como el arma principal -que no la única- a disposición del orador (Peel 1995: 76). Por su parte, Bang-Rouhet (2009: 93) define la voz como «... el alma humana porque hay varias ma-

\footnotetext{
${ }^{1}$ Con comillas angulares en el original.
} 
neras de utilizarla, de proyectarla, de reprimirla». Se debe poner cuidado en el interés y el significado de lo que se está diciendo, siempre teniendo presente que se ha de explotar al máximo la voz, puesto que el significado es transmitido a través de variaciones en el ritmo, el timbre y el volumen (Peel 1995: 77).

Ciertamente, como indican Briz et alii (2008: 120), «una voz agradable capta más fácilmente la atención del auditorio», a la vez que recuerdan la supremacía de cómo se ejecuta el discurso frente al valor único de la comunicación verbal. Poseer una buena voz para hablar en público facilita el éxito del orador; no obstante, no se trata de una condición indispensable. Es más, se registran bastantes casos de oradores que han sabido conectar con el auditorio a pesar de no poseer una voz agradable, dado que se sirvieron de habilidades retóricas y expresivas tanto para argumentar como para seducir; en definitiva, consiste en simultanear la explicación de las ideas con el contagio de sentimientos (Vilà 2014: 106).

Entre los requisitos que conforman las cualidades de la voz están: el volumen, la velocidad, el tono, las pausas y la flexibilidad (Briz et alii 2008: 121). Por su parte, Tierney (1998: 57) considera que una correcta elección del tono del discurso implica que el orador se gane al auditorio capacitándolo y escuchándolo; por el contrario, si la elección no es adecuada, se puede perder al auditorio ofendiéndolo, con una actitud paternalista, denigrándolo, insultándolo o asustándolo. Sobre la vocalización, se ha de observar que la falta de la misma es un defecto muy frecuente en la comunicación, como consecuencia de una infravalorización del canto de las sílabas o las consonantes (Bang-Rouhet 2009: 100). Por flexibilidad se entiende la capacidad que tiene el orador para modificar las cualidades de su voz, como son el volumen, el tono, la velocidad, la entonación y la duración de las pausas; estos cambios están sujetos al interés persuasivo con el objetivo de evitar la monotonía expresiva (Briz et alii 2008: 125). Como señala Bang-Rouhet (2009: 110), la alternancia del ritmo permite asignar una melodía en el texto, otorga color a las palabras y facilita su interpretación. A su vez, aboga Couto (2002: 90) por la necesidad de cuidar la voz, aspecto bastante olvidado por buena parte de los individuos. Algunas cuestiones que permiten mejorar cómo suena la voz son la respiración, la posición de la lengua en la articulación o el movimiento de los labios.

Según Vilà (2014: 105), la diferencia entre un orador experto y uno novel radica en que este último se dedica a recitar textos memorizados de forma que no existe armonía entre el contenido del discurso y la entonación empleada, mientras que el primero sabe manejar tanto la modulación de la voz como el ritmo y el silencio. «El sentido de las palabras no tiene valor si el orador no les da la dimensión emocional, si el orador no hace el esfuerzo de poner en evidencia su sentido escondido» (Bang-Rouhet 2009: 
92). Por ello, el hablante no puede pensar que simplemente con pronunciar el discurso es suficiente para persuadir a su auditorio, pues el discurso ha de transmitir emociones para que este proceso de convencimiento sea posible (Bang-Rouhet 2009: 92). Leith, a propósito de la acción, indica: «El mejor consejo sigue siendo: sé tú mismo, pero ese principio, como sugiere la relación entre la acción retórica y la actuación, no lo es todo. El buen orador se interpreta $a^{2}$ a sí mismo, y lo hace utilizando la técnica de la inmersión total de un actor del método» (2012: 212).

No se ha de caer en el error de buscar el lucimiento personal con formas muy refinadas o con un lenguaje bastante críptico que no llega a ser entendido por el auditorio, porque esta utilización de un lenguaje falsamente culto o artificioso a menudo esconde incompetencia, además de que el léxico no frecuente transmite pedantería (Rubio Cebrián y Rubio González 2014: 38). Sobre la fluidez verbal Rubio indica: «No se trata sólo de un don natural, sino que, como todo, también se aprende. Aprender, no obstante, supone esfuerzo, es decir, voluntad. Si realmente tenemos el deseo y el convencimiento de querer emprender la tarea de hablar en público adecuadamente, serán ineludibles dos aspectos: trabajo y experiencia» (2004: 54).

Saber utilizar de manera correcta la pausa y el silencio denota que el orador es experimentado (Vilà 2014: 110). «El silencio es un discurso, por muy paradójico que parezca comunica muchísimo más que un ciento de palabras dichas a borbotones y sin respiro» (Garrido 2007: 91). Los silencios ayudan tanto al orador como al público. Cuando están bien estructuradas las pausas, colaboran con el discurso en tanto que obtienen un ritmo de reflexión y de consolidación de lo que se ha comunicado previamente. El silencio no debe asustar al orador, quien no ha de tener prisa por terminar ni tampoco ha de sentir miedo por no incluir en su discurso todo el contenido que llevaba preparado, puesto que en realidad adquiere más relevancia interaccionar con el auditorio y resaltar el contenido más importante (Garrido 2007: 92). Para Briz et alii (2008: 124), la pausa permite al auditorio reflexionar sobre el discurso que acaba de presenciar. Asevera Bang-Rouhet (2009: 112) que las pausas crean expectativas y suspense, hasta el punto de que promueven la concentración auditiva del público.

Ratifica Couto (2002: 93) que las pausas se utilizan fundamentalmente para: por un lado, llamar la atención del receptor y permitir que este reflexione sobre lo que ha escuchado, y, segundo, este tiempo de silencio puede ser aprovechado por el hablante para ordenar sus pensamientos y retomar su discurso. El orador no debe temer utilizar pausas ni, por supuesto, ha de emplear ruidos innecesarios para rellenar tales silencios. Aparte

\footnotetext{
${ }^{2}$ En cursiva en el original.
} 
de las funciones ya mencionadas, Rubio Cebrián y Rubio González también defienden que las pausas pueden usarse para marcar las transiciones en los cambios temáticos del discurso (2014: 45). Cuando el orador pierde el miedo a dejar silencios en su discurso es precisamente el momento en que este individuo comienza a controlar la situación (Rubio 2004: 51).

\section{LA COMUNICACIÓN PARAVERBAL EN MANUALES ESPAÑOLES DE ELOCUENCIA FORENSE DEL SIGLO XIX}

En los fondos de la Biblioteca Nacional se han encontrado siete manuales publicados en España sobre elocuencia forense en el siglo XIX. Se ha establecido un orden cronológico para describir de manera detallada la información que incluyen tales libros sobre comunicación paraverbal.

\subsection{Sainz de Andino (1847[1828])}

La temprana obra de Sainz de Andino (1847[1828]) dedica el capítulo sexto a la recitación; este presenta una estructura bipartita para explicar tanto la voz como los gestos. Comienza el epígrafe que aborda la voz reflexionando sobre la variedad de sentimientos que se transmiten a través de ella: humildad, arrogancia, dulzura, soberbia, suavidad o fiereza; de manera que proyecta amor, odio, indignación, benevolencia, placer, pena, dolor, admiración u horror; a la vez que constituye «... el correo fiel de nuestra alma, y el ministro que publica sus pensamientos, sus intenciones y su voluntad ${ }^{3} \gg(1847$ [1828]: 178). Sostiene que debe discriminarse entre el eco (calidad del sonido), la fuerza (que se puede aumentar o disminuir) y la melodía (suavidad que le confiere de gracia, dulzura, afecto y armonía) (1847[1828]: 179).

Define la entonación como «... el grado de elevacion ó de fuerza que se da á la voz, el cual debe graduarse segun sean el hueco del local en que se pronuncia el discurso, la forma de su construccion y la concurrencia de las gentes...» (1847[1828]: 180). Además, distingue los tonos de voz alto, mediano y bajo; en particular, observa que los tonos altos se utilizan para expresar pensamientos extraordinarios, así como los sentimientos de ira, odio y horror; si bien no se ha de dar en todos los casos de la recitación oratoria. Tras diversas disquisiciones sobre el tono más adecuado, apuesta por la equiparación del tono de la locución pública con una conversación

${ }^{3}$ En todas las citas literales de este artículo se ha respetado escrupulosamente la escritura de las fuentes originales. 
tan interesante como animada, a la vez que grave y majestuosa; a la par, advierte del error de caer en la monotonía del tono, dado que con este fallo «... se le quita el alma al discurso...» (1847[1828]: 181) propiciando el aburrimiento del auditorio. En suma: «No hay cosa mas insulsa que un tono musical, artificioso, afectado y uniforme» (1847[1828]: 181).

Con respecto a la articulación, este autor entiende que es una parte indispensable consistente en «... la espresion clara y distinta de las letras y sílabas que componen las palabras...» (1847[1828]: 181). Asevera explícitamente que, si la articulación no es correcta, no se puede entender al orador. Por tanto, insta a una articulación clara, pero no forzada, carente de precipitación y volubilidad. También dilucida que ha de existir armonía entre expresión y pensamiento, puesto que se deben expresar con lentitud ciertos discursos para que adquieran peso y dignidad, frente a la agitación propia de pensamientos más acalorados. La observación y la práctica resultan claves para adquirir dominio tanto en el tono como en la articulación.

Entiende por acento oratorio la modulación de la voz. Con estas palabras distingue entre acento oratorio y entonación: «... esta rige el tono general y comun del discurso, acomodado para que el concurso pueda oirlo; y el acento oratorio ciñe su accion á sílabas determinadas, cuya espresion esfuerza por medio de una detencion ó prolongacion en la articulacion de ellas, sin variar de tono» (1847[1828]: 183). De esta manera, distingue entre el acento de la cólera, el miedo o el placer. Sobre esta cuestión, pone el punto de mira en la exageración en el empleo del acento oratorio, porque le otorgaría un halo de teatralidad que desemboca en el ridículo. Para evitar tal defecto, apuesta por la naturalidad a la hora de transmitir los sentimientos. Una vez más, insiste en la práctica como medio para superar este error, sobre todo en los casos en que el orador ha escrito con anterioridad su discurso, poniendo especial atención en las palabras que quiere enfatizar para que no haya un número abusivo de tales intensificaciones.

Igualmente, tienen cabida algunas reflexiones sobre las pausas. El autor -desde una perspectiva funcional- se percata de que las pausas sirven tanto para llamar la atención sobre una determinada parte del discurso aportando sobriedad como para señalar las divisiones de dicho discurso. Hay que tener en cuenta la existencia de pausas fisiológicas, con las cuales el orador debe ser hábil en su empleo para no dejar una pausa en una parte del discurso que cree confusión. Acorde con los postulados de Quintiliano, sostiene que las pausas y el estilo han de albergar las mismas características: corrección, claridad, adorno y congruencia. Cierra este apartado dedicado al paralenguaje con un discurso que está a caballo entre la necesidad y la crítica: 
El mismo lustre de la abogacía exige que desaparezcan para siempre de los tribunales los gritos descompasados, las entonaciones destempladas, los acentos furibundos con que algunos letrados, en vez de esforzar la defensa y lucir su ingenio oratorio, como tienen la sandez de creerlo, no hacen mas que abusar de la indulgente tolerancia de los magistrados, fastidiar al auditorio y desacreditar sus trabajos (1847[1828]: 186).

\subsection{Enciso Castrillón $(1840)^{4}$}

Este autor aborda de manera conjunta y comparativa la comunicación paraverbal en los géneros sagrado y forense. Considera que, si se elimina del discurso una pronunciación firme, clara y corriente, este quedaría sin efecto. Además, indica que se ha de ensayar «... la estension de su voz y buscando los puntos mas sonoros para ponerse de antemano en escena con los oyentes, sobre los cuales se debe ejercer el imperio de la palabra» (1840: 293). Un poco más adelante, sostiene que los movimientos del alma han de estar acompañados por distintas inflexiones de la voz, como es elevarla, la transmisión de dulzura, la pronunciación lenta o bien precipitada, características que señalen los matices de los sentimientos que el orador quiere expresar o bien desee excitar al auditorio (1840: 293-294). Esgrime que el orador debe dirigir su voz al frente, evitando orientarla hacia los laterales. Sigue con más consejos: «Articúlense claramente todas las palabras: téngase particular atencion en distinguir los finales de cada periodo, mediante un sonido mediano, y síganse en cuanto sea posible la puntuacion que se ha puesto en el escrito» (1840: 298-299).

Afirma que el buen orador ha de distinguir entre los tonos grave, medio y agudo del órgano de su voz; considera que el tono más adecuado es el medio, dado que así puede elevarlo o bajarlo según convenga, al tiempo que critica un excesivo volumen alto. Recoge la tesis de Quintiliano de que la pronunciación sea seguida -que no precipitada- y siempre arreglada, pero sin dejar de resultar lenta. También advierte sobre la rapidez excesiva en la pronunciación y sobre que las pausas carentes de sentido desconciertan al auditorio. El buen orador ha de: «Variar las inflexiones á cada figura y las entonaciones á cada párrafo» (1840: 305). Tanto en la acción como en la composición aconseja imitar los acentos simples y apasionados, al

${ }^{4}$ Tan solo se ha consultado el volumen I, dado que el II no se ha podido localizar ni en los fondos de la Biblioteca Nacional. Se ha de observar que durante los siglos XVI y XVII -como consecuencia de la relevancia de la práctica religiosa- la actio es considerada parte de la retórica sagrada; su presencia resulta habitual en los libros de predicación que vieron la luz durante el Siglo de Oro, hasta el punto de que en el siglo XvIII tanto la actio como la pronunciación monopolizan el cuarto libro de la Retórica de Mayans (Albaladejo 1990: 170-172). Esto explica que esta obra abarque la elocuencia sagrada y la forense. 
igual que intercalar en el discurso rasgos oratorios de reposos o silencios, los cuales son percibidos como excelentes cuando resultan poco comunes y están correctamente ubicados.

\subsection{Corradi (1843)}

Este libro defiende que globalmente el gesto, la acción y las inflexiones de la voz complementan la información que se transmite a través de las palabras. La situación del alma indica si la entonación asciende o desciende, es tranquila o precipitada, trémula o firme y la voz recorre desde las formas más agudas a las más graves. «Verdad es que entre los antiguos la pronunciacion era mas esencial aun que entre nosotros» (1843: 128). Aparte, admite que el auditorio del orador está atento «... á todo aquello que hiere los ojos y conmueve el corazon» (1843: 128). La pronunciación ha de ser clara, correcta y fácil, puesto que si no es adecuada no solo resulta desagradable al oído sino que también desluce el discurso. De hecho, «la mala pronunciacion tiene ademas el inconveniente de embarazar al orador en el vuelo de su improvisación, porque le detiene, distrae y hace perder el hilo de las ideas» (1843: 129). Dilucida que la buena calidad y la afinación del instrumento de la voz están influidas tanto por la naturaleza como por el arte. Cita a Quintiliano al indicar que la voz debe ser fácil, natural y agradable, de tal forma que exista sintonía con las conmociones del ánimo. Observa que tanto si la entonación es demasiado elevada o demasiado baja provoca disgusto y cansancio en el auditorio. Igualmente, aboga por el término medio con respecto a la velocidad del discurso, por lo que el orador tiene que ser hábil para sostener sin violencia y distribuir los descansos. Sobre las pausas señala dos empleos: de una parte, las propias relacionadas con la necesidad de respirar, y, de otra parte, las utilizadas estratégicamente para centrar la atención del auditorio.

«El buen uso de la voz forma la armonía y cadencia oratoria, ó mejor dicho, la música de la elocuencia. ¡Dichoso el orador que posea una voz sonora, flexible, pura, grave y melodiosa!» (1843: 132). Las distintas emociones -como son dolor, alegría, cólera y templanza- han de ser expresadas con distintos acentos. A la par, argumenta que la igualdad y la variedad constituyen los dos requisitos fundamentales de la voz. La igualdad tiene como objetivo moderar y dirigir, de manera que permite que el orador pase de los puntos graves a los agudos. En cambio, la variedad ha de evitar tanto la monotonía como el martilleo de la entonación. Del mismo modo, reflexiona que el gesto ha de acompañar a la voz: «Este sigue la voz ó la precede, dándola fuerza y espresion, ó parte al mismo tiempo á impulso de la pasion que nos afecta, y completa la significacion de las pala- 
bras, añadiendo lo que estas callan, ó no alcanzan á decir á causa de su natural insuficiencia» (1843: 134).

\subsection{Sauri y Lleopart (1847)}

Abre Saurí y Lleopart el capítulo sobre la acción recordando que conforma una parte esencial en el discurso, para lo cual incluye la conocida teoría de Demóstenes de que la acción asume toda la fuerza de la elocuencia. Así pues, Saurí y Lleopart ratifica esta idea de la siguiente manera: «... el que habla no solo las [sus ideas] manifiesta con sus palabras y con sus acciones, sino tambien con el tono de su voz, con sus ojos, con sus gestos y con todo su exterior; y no pocas veces da á entender lo que fuera muy peligroso de expresar» (1847: 41). Aparte, asume que la voz es como un medio que logra transmitir las emociones: «... por el órgano de la voz expresa los sentimientos de que nos hallamos poseidos» (1847: 42).

\subsection{Pérez de Anaya (1848)}

La comunicación paraverbal en la obra de Pérez de Anaya no es abordada de manera directa. Al tratar la poesía, alude de soslayo a la pronunciación: «Convendrá no obstante huir la frecuencia de los versos mayores, en especial al principio ó fin del período, donde se notan mas, y evitar sobre todo los octosílabos, cuando formen un miembro, que deba pronunciarse con separacion» (1848: 110). Unas líneas más adelante defiende que la dicción poética no puede guardar el orden lógico del lenguaje, entendiendo por tal el curso tranquilo y continuado denominado fluidez, a la vez que ha de «... plegarse á la marcha contraida y artificiosa del verso» (1848: 111).

\subsection{López (2013[1849])}

Por su parte, López habla en estos términos sobre los aspectos concernientes a la comunicación paraverbal: «La voz debe tener cierta gravedad y ser siempre en su acento comedida y respetuosa. La entonacion ha de empezar en una cuerda media aunque con mucha claridad siempre, porque asi puede despues sin fatiga subirse ó bajarse segun lo reclame la necesidad de espresar las afecciones» (2013[1849]: 353). Indica explícitamente que la agitación o no de la voz ha de ser coherente con el tipo de discurso emitido, igual que ocurre con la velocidad y con el timbre. Aboga con firmeza por el cambio de la entonación y del acento para no caer en el aburrimiento: «Hay conceptos que piden una inflexion mas marcada en la voz, y si esta 
falta, desaparece todo el encanto. Esto es lo que se llama énfasis, que es el auxiliar mas poderoso en boca de un abogado diestro y entendido» (2013[1849]: 354). La relevancia de la voz la justifica de esta manera: «La voz tiene en sí misma, su música, y su poesía; y cuando se desdeña ó se olvida, solo queda una prosa repugnante é insoportable» (2013 [1849]: 355). Sobre las pausas destaca las siguientes ventajas: permiten al orador pensar, a la vez que aportan serenidad y autocontrol (2013[1849]: 355).

\subsection{León y Olarrieta (1862)}

En este libro se ha aludido a la comunicación paraverbal de forma tangencial. Según León y Olarrieta, es la práctica la mejor vía para mejorar el arte de hablar en público, junto a la escritura, el trato social y la lectura de autores doctos en oratoria; del mismo modo, insta al hábito como técnica efectiva para obtener éxito en este terreno (1862: 42). Con respecto a la vocalización, expresa literalmente: «... á los ejercicios de vocalizacion que verifican los cantores para dominar las fibras de su garganta...» (León y Olarrieta 1862: 43).

\section{DisCUSIÓN Y CONCLUSIONES}

Los manuales examinados en este artículo -esto es, libros sobre elocuencia forense publicados en el siglo XIX- eran utilizados principalmente para apoyar la formación docente de los estudiantes de derecho; la obra de Enciso Castrillón (1840) también instruye en el contexto sagrado, la de Corradi (1843) en el área parlamentaria y la de López (2013[1849]) en los ámbitos parlamentario y de improvisación. Los autores son conscientes de que un buen orador ha de prestar atención a la actio y, en particular, a la comunicación paraverbal, cuestión sobre la que se centra la presente investigación. El denominador común existente en los trabajos estudiados es entender la práctica como la clave para mejorar en el arte de hablar en público, así como apostar por adecuar la comunicación paraverbal y no verbal al contenido del discurso emitido. No todas las publicaciones analizadas le otorgan al paralenguaje la misma relevancia; en particular, esta cuestión es abordada con mayor profundidad en Sainz de Andino (1847[1828]), Enciso Castrillón (1840) y Corradi (1843), frente a una menor presencia de este tema en Saurí y Lleopart (1847), Pérez de Anaya (1848), López (2013[1849]) y León y Olarrieta (1862).

Es precisamente en el primer manual publicado -Sainz de Andino (1847[1828])-donde se puede leer información más detallada sobre la 
comunicación paraverbal; de hecho, hasta incluye un apartado específico para la pausa. Este autor sostiene que a través de la voz el orador puede transmitir sentimientos muy dispares; del mismo modo, se detiene en instruir al orador en la correcta adecuación de la entonación, la articulación y la modulación de la voz (esto último lo denomina acento oratorio). Este libro insiste en no excederse en la comunicación paraverbal, porque el hablante proyectaría un halo de teatralidad, lo cual desembocaría en una imagen ridícula.

Desde el enfoque conjunto de la elocuencia sagrada y forense, Enciso Castrillón (1840) arguye que la pronunciación clara resulta fundamental para que el discurso provoque los efectos oportunos en el receptor. Igualmente, centra la atención en la necesidad de tener en cuenta la actio cuando se compone el discurso, y justo al revés, o sea, cuando se ejecuta el discurso se ha de partir de lo establecido en la composición. Considera que a través de la voz se cifran los sentimientos del orador, de ahí que haga hincapié en las inflexiones de la voz. También incluye indicaciones sobre la correcta proyección de la voz. Sin embargo, Corradi (1843) trata juntamente la comunicación paraverbal y la comunicación no verbal, las cuales han de ir en sintonía con miras a la consecución de un discurso adecuado. Advierte de que la mala pronunciación no solo resulta desagradable, sino que empaña el discurso. A su vez, observa que en la voz influyen tanto la naturaleza como el arte. Enjuicia que las diversas emociones han de ser expresadas con distintos acentos. Además, utiliza la locución música de la elocuencia para expresar el correcto uso de la voz.

De otro lado, Saurí y Lleopart (1847) indica explícitamente que a través de la voz el orador transmite sus sentimientos. En la obra de Pérez de Anaya (1848) se trata la voz de manera indirecta cuando aborda la poesía, pues el autor contrasta el género literario de la poesía con el orden lógico del lenguaje. En cambio, López (2013[1849]) aporta consejos sobre la comunicación paraverbal que ha de seguir el orador con el fin de ubicarse en el punto preciso de agitación o tranquilidad de su discurso, al tiempo que advierte sobre el error de la monotonía; aparte, recuerda que la voz posee cualidades propias de música y de poesía. La obra de León y Olarrieta (1862) es la que menos se ocupa de la cuestión aquí examinada, pues tan solo de forma indirecta alude a ejercicios de vocalización.

En concreto, el empleo de la pausa ha captado la atención de cuatro de los manuales examinados. De esta manera, Sainz de Andino (1847[1828]) y Corradi (1843) evocan que las pausas resultan necesarias fisiológicamente para que el orador pueda respirar. Asimismo, las pausas pueden ser utilizadas para lograr llamar la atención del auditorio sobre una parte concreta del discurso (Sainz de Andino 1847[1828] y Corradi 1843). Otras funciones de la pausa son: marcar las distintas partes de las que se compone un 
discurso (Sainz de Andino 1847[1828]), permitir pensar al orador y transmitir tranquilidad y autocontrol (López 2013[1849]). Desde un enfoque ligeramente diferente, Enciso Castrillón (1840), de una parte, se percata de que si la pausa está mal utilizada crea desconcierto en el público, y, de la otra, obtiene magníficos resultados una pausa que esté correctamente situada y cuyo uso no sea excesivamente común. Grosso modo, la información que aparece sobre las pausas en los manuales examinados del siglo XIX es la misma que está presente en obras más actuales, como en Couto (2002), Rubio (2004), Garrido (2007), Briz et alii (2008), Bang-Rouhet (2009), Rubio Cebrián y Rubio González (2014) o Vilà (2014).

$\mathrm{Al}$ contrastar la relevancia que asume la comunicación paraverbal en trabajos de elocuencia forense publicados en el siglo XIX con libros sobre comunicación que han visto la luz durante el siglo XX y el XXI, se puede aseverar que en realidad el panorama no es muy diferente. Aunque Mehrabian (1972) le otorgó un $38 \%$ y van-der Hofstadt (2005) una horquilla que oscila entre el 40 y el $50 \%$ a la información que transmite el hablante mediante la voz, el enfoque tradicional apuntaba a un $33 \%$. Junto a ello, en la actualidad hay publicaciones con un marcado perfil tradicional estructuradas en torno a las cinco conocidas fases de elaboración del discurso -tal es el caso de las obras de Albaladejo (1990) o Morales (2007)-; si bien es cierto que hoy en día las investigaciones de esta índole suelen mostrar una firme preferencia por indagar tanto en comunicación paraverbal como en comunicación no verbal, en detrimento del clásico monopolio que asumía la comunicación verbal. A pesar de la longa y fecunda trayectoria que poseen los estudios sobre hablar en público, los trabajos más contemporáneos sobre esta cuestión desvelan información sobre el proceso de emisión y recepción de un mensaje, en tanto que para el orador dichos conocimientos le resultarán fundamentales a la hora de cifrar el mensaje, mientras que al público le permite ser más consciente de cómo ha de entender correctamente el discurso que ha presenciado. 


\section{BIBLIOGRAFÍA}

Albaladejo, Tomás (1990): Retórica, Madrid: Síntesis.

BAng-Rounet, Pascale (2009): ¿QQué nos jugamos cuando hablamos en público?, Barcelona: Alienta Editorial.

BRIZ, Antonio et alii (2008): Saber hablar, Madrid: Santillana Ediciones Generales.

CiCERÓn (2013): El orador, Madrid: Alianza Editorial.

CoRradi, Fernando (1843): Lecciones de elocuencia forense y parlamentaria, Madrid.

CORTÉs, Luis (2017): «La enseñanza de la lengua oral: pariente pobre de nuestro sistema educativo», Tonos Digital 33, 1-14. <http://www.tonosdigital.es/ojs/ index.php/tonos/article/viewFile/1732/913>.

Couto, Manuel (2002): Cómo hablar bien en público. Comunicar, persuadir y convencer con palabras, Barcelona: Gestión 2000.

EnCiso CASTRILlón, Félix (1840): Lecciones y modelos de elocuencia sagrada y forense. Tomo I. Elocuencia sagrada, Yenes.

GARRIDO, Emilio (2007): Aprenda a hablar en público, ¡no tenga miedo!, Navarra: Ulzama.

Hernández Guerrero, José Antonio y Mari Carmen García Tejera (2008): El arte de hablar. Manual de retórica práctica y de oratoria moderna, Barcelona: Ariel.

LABORDA GIL, Xavier (2014): Inteligencia emocional, Barcelona: Plataforma Editorial.

LeITH, Sam (2012): ¿Me hablas a mí? La retórica de Aristóteles a Obama, Madrid: Taurus.

LEÓN y OlARRIETA, Fernando de (1862): Consideraciones filosóficas sobre la elocuencia forense, El Valenciano.

LóPEz, Joaquín María (2013[1849]): Lecciones de elocuencia en general: de elocuencia forense parlamentaria y de improvisación, $\mathrm{S}$. N.

Mehrabian, Albert (1972): Nonverbal Communication, Chicago: Adeline-Atherton.

Morales, Carlos Javier (2007): Guía para hablar en público. Método completo y práctico para las más diversas situaciones, Madrid: Alianza Editorial.

ORZÁız, Óscar (2009): «Comunicación no verbal y paraverbal en el debate político entre Zapatero y Rajoy», Tonos Digital 18, 1-22. <https://www.um.es/tonos digital/znum18/secciones/tritonos-2-noverbalidad.htm>.

PeEL, Malcolm (1995): Aprenda a hablar en público en una semana, Barcelona: Plaza \& Janés.

PÉrez de AnAYA, Francisco (1848): Lecciones de elocuencia forense, González.

Poyatos, Fernando (1994): La comunicación no verbal. I. Cultura, lenguaje y conversación, Madrid: Istmo.

Rubio Cebrián, Santiago y Beltrán Rubio GonzÁlez (2014): El buen comunicador, Madrid, Editorial Grupo 5.

Rubio, Ángeles (2004): Cómo ser un buen orador, Barcelona: Ediciones Gestión 2000. 
SAINZ DE ANDino, Pedro (1847[1828]): Elementos de elocuéncia forense, Julian Viana Razola. <http://fama2.us.es/fde/ocr/2006/elementosDeElocuenciaForen se.pdf $>$.

SÁnCHEz PÉREz, José (2015): Cómo comunicar y ser competente: habilidades comunicativas y competencias académicas y profesionales, Madrid: Atelier.

SAURí y LleOPART, Ramón (1847): Elocuencia forense, Herederos Vda. Pla.

TIERNEY, Elizabeth (1998): 30 minutos... para mejorar sus destrezas comunicativas, Barcelona: Granica.

VAN-DER HOFSTADT, Carlos (2005): El libro de las habilidades de comunicación, Madrid: Ediciones Díaz de Santos.

VILÀ, Montserrat (2014): 10 ideas clave: enseñar la competencia oral en clase: aprender a hablar en público, Barcelona: Graó. 